\title{
A experiência cultural da leitura
}

Richard Romancini

Doutor em Ciência da Comunicação pela Escola de Comunicações e Artes da Universidade de São Paulo, onde também é pesquisador e colaborador. Professor da Faculdade de Educação e Cultura Montessori - Famec/SP.

E-mail: richard.romancini@gmail.com

Resumo: O texto discute o papel da escola na formação de leitores e as atitudes que essa instituição deve ter diante de textos de ampla circulação. Argumenta que a leitura como uma experiência cultural alicerça-se na articulação entre o ato de ler e a cultura cotidiana do leitor, destacando que a escola deve propiciar a aquisição de uma competência de leitura para enraizar esta prática.

Palavras-chave: leitura, escola, best-seller, biblioteca, alfabetização.
Abstract: This text discusses the role of schools in shaping of readers and what it should do with the texts of wide circulation. Argues that reading is a cultural experience based on the relationship between this activity and reader's everyday culture, stressing that schools should be able to offer a competence in reading, for rooting this practice.

Keywords: reading, school, best seller, library, literacy.

A partir da informação de que o governo paulista distribuiria no segundo semestre de $2009^{1}$ dois milhões de livros para a leitura a 4.200 escolas, e que entre os 220 títulos comprados estariam exemplares das séries Harry Potter e Crepúsculo, o site UOL criou um Grupo de Discussão para a troca de opiniões sobre o assunto. As perguntas básicas eram as seguintes: Qual sua opinião sobre oferecer livros de Harry Potter nas escolas? Isso pode estimular o leitor ou afastá-lo dos clássicos ${ }^{2}$ ?

Essa notícia aponta para uma discussão recorrente a respeito das práticas de leitura, em particular as que envolvem a escola. A questão problemática diz respeito à contraposição entre as supostas leituras literárias sérias, isto é, aquelas que fazem parte de certo cânone, os clássicos literários abrigados pelos currículos e as leituras vistas como não sérias ou de simples entretenimento. A série Harry Potter, as novelas sentimentais como Sabrina e os livros de Paulo Coelho são classificados nesta segunda categoria; Machado de Assis, Graciliano Ramos e Guimarães Rosa, na primeira. Esses autores são privilegiados pela escola, já que esta é a instância de transmissão cultural, por excelência, dos conteúdos e competências legitimados socialmente; mas que procedimento a escola deve adotar ante o best-seller e outras modalidades textuais de ampla circulação (como as novelas de banca de jornal e as histórias em quadrinhos) menos consagradas? Esse é o aspecto central subjacente à questão.

2. Disponível em: <http://forum.educacao.blog.uol.com.br/ arch2009-03-08_200903-14.html\#2009_0309_15_27_28-8953204$0>$. Acesso em: 16 mar. 2009. 
comunicação \& educação • Ano XV • número 2 • maio/ago 2010

3. ROMANCINI, Richard. Apropriações de Paulo Coelho por usuários de uma biblioteca pública: leitura popular, leitura popularizada. Dissertação (Mestrado)-Escola de Comunicações e Artes, Universidade de São Paulo, 2002.

4. AMORIN, Galeno (Coord.). Retratos da leitura no Brasil: relatório de pesquisa promovida pelo Instituto Pró-Livro, 2008 Disponível em: <http:// www.prolivro.org.br/ipl/ publier4.0/dados/anexos/48.pdf $>$. Acesso em: 12 nov. 2009

5. Cf. SÁ EARP, Fábio; KORNIS, George. A economia do livro: a crise atual e uma proposta de política. IE/UFRJ. Texto para Discussão n. 004/2005, 2005. Disponível em: <http://www. ie.ufrj.br/publicacoes/ discussao/a_economia do_livro_a_crise_atual_e uma_proposta_de_politica.pdf>. Acesso em: 12 nov. 2009.

6. Cf. JOUVE, Vincent. A leitura. São Paulo: Ed. Unesp, 2002. p. 76-77.
O interesse por essa notícia relaciona-se ao estímulo à continuidade de uma reflexão que se tornou importante durante uma pesquisa com leitores de Paulo Coelho, na qual o universo escolar adquiriu relevo ${ }^{3}$. Alguns dos dados empíricos dessa pesquisa que embasam a compreensão da leitura como uma experiência cultural são abordados ao longo do texto. O principal aspecto, vale ressaltar, é o vivo contraste, notado nos depoimentos dos leitores de Paulo Coelho, opondo as práticas escolares de leitura (geralmente, pouco marcantes e sem maior interesse) à leitura do autor mencionado. Esta era, em vários aspectos, mais intensa, projetando-se em experiências cotidianas e na avaliação dos leitores de que, por meio dos livros de Paulo Coelho, obtinham "prazer" e "conhecimento". A análise final concluía que a leitura literária escolar era vivida sob os termos da obrigação e do desprazer e, nesse sentido, contraposta à leitura de Paulo Coelho. Com efeito, a escola brasileira, de maneira geral, forma poucos leitores. Dados de uma pesquisa realizada no Brasil em $2007^{4}$ mostram uma provável diminuição da frequência a bibliotecas com o fim da vida escolar: $62 \%$ dos adolescentes utilizam-nas, enquanto o percentual de adultos nessa situação é de 20\%; e, no grupo das pessoas de 50 anos, apenas $12 \%$. A mesma pesquisa mostra que, dentre as principais limitações para que se leia, a realização de uma leitura muito vagarosa é uma barreira declarada por estimados 28,1 milhões de brasileiros. Esta realidade reflete-se na inexistência de um amplo mercado para o livro. No Brasil, há a compra de dois exemplares per capita (contra 11 no Japão) e as baixas tiragens fazem com que o preço do livro, relativo ao poder de compra da população, seja alto $^{5}$. Desse modo, percebe-se que as questões relativas à leitura são complexas, envolvendo variáveis econômicas, sociais e culturais.

Porém, é interessante, nesse contexto, pensar nas relações entre a escola, a formação de leitores e a circulação e uso dos textos massivos que a circundam e nela penetram pelas leituras dos estudantes. Antes de abordar esses aspectos, é válido explicar o que se entende pelo termo experiência cultural da leitura, cuja utilidade é ressaltar que esta prática (vista como o ato de decodificar e dar sentido a códigos gráficos, que representam a língua falada) tem um antes e um depois, os quais influenciam o ato de ler.

\section{A EXPERIÊNCIA CULTURAL DA LEITURA}

Os analistas do processo cognitivo da leitura descrevem bem o papel da memória e da sua antecipação, isto é, a necessária dialética entre os conhecimentos que se adquiriram na leitura e a previsão, com base na formulação de hipóteses, do que pode ocorrer na sequência do texto. A validação ou invalidação das hipóteses faz com que o leitor requestione suas interpretações e construa novos sentidos para o que lế ${ }^{6}$. No entanto, essa compreensão do processo de leitura tende a se fixar nos limites do texto e do ato de ler. $\mathrm{O}$ entendimento da leitura como uma experiência cultural compreende as múltiplas dimensões dessa prática no tempo. Existe um passado amplo entre o leitor e o texto, que 
A experiência cultural da leitura - Richard Romancini

envolve as suas motivações (informar-se, divertir-se etc.) e seu estoque de conhecimentos, entre outros aspectos, e as implicações tiradas pelo sujeito a partir do que lê, que se projetam em suas ações e condutas. Estas podem possuir um teor mais pessoal, com modificações na visão de mundo, no desejo de ler outros livros, ou social, estimulando interações com outros leitores, por exemplo.

O destaque para este contexto, isto é, o antes e o depois que envolvem a relação de um leitor com determinada prática de leitura, tem o mérito de evitar que se dê uma centralidade excessiva ao texto, no entendimento do processo de aquisição e formação cultural relativo à leitura. Isto é importante, em particular, na discussão do binômio leitura/escola. Assim, é possível dizer que existem leituras de livros sérios, julgados relevantes - por isso, adotados nas escolas, por representarem o que se considera uma realização cultural e literária exemplar -, entretanto, com significações pífias em termos da vida de certos estudantes/leitores. São leituras que, incapazes de em determinado contexto melhorar a capacidade de leitura do indivíduo, são realizadas com desprazer e tédio e, por isso, não provocam o desejo de novas experiências no consumo de textos similares. De modo geral, foi isso que se observou no caso dos leitores de Paulo Coelho na pesquisa mencionada ${ }^{7}$. Ao contrário, certas leituras menores podem ter um rendimento mais significativo, ou pelo menos mais importante do que se poderia esperar, com a ampliação dos conhecimentos e interações sociais por parte de um indivíduo, algo que também foi notado na pesquisa citada. Essa não é uma regra e pode ocorrer ainda que os estudantes rejeitem ambos os tipos de leitura, em prol de outras atividades. A despeito disso, o alerta recomenda não idealizar ou condenar certo consumo, de modo prévio; chama a atenção, ainda, para as experiências e competências dos leitores como elementos que favorecerão as apropriações de um texto.

Ancorar um texto na vida de um leitor (ou melhor, fazer com que ele tenha o desejo de realizar essa operação) não é tarefa fácil. Ele pode, muitas vezes, sentir profundo alheamento em relação a tal leitura. Em certo sentido, a concorrência com outras práticas culturais e com a leitura massificada é também um complicador. Porém, esses elementos não devem representar barreiras absolutas às formas de aquisição cultural que a escola objetiva, quanto à cultura letrada. Maximizar as dificuldades, ao esquecer as possibilidades de sinergia entre as práticas culturais, ou alimentar preconceitos, como a suposta exclusividade de um regime de leitura, são aspectos que podem dificultar a desejável ampliação do universo de leituras escolares significativas. Nesse sentido, são atitudes que se devem evitar.

\section{BIBLIOTECAS E O USO SOCIAL DOS TEXTOS}

A leitura, inclusive a literária, possui um horizonte pragmático com frequência maior que aquele que os intelectuais e professores estão dispostos a admitir. Lemos não somente para obter um enriquecimento cultural genérico, mas também para utilizar as capacidades adquiridas através da leitura. Bourdieu 
comunicação \& educação • Ano XV • número 2 • maio/ago 2010

notou que a necessidade da leitura não é evidente, embora pareça assim aos que fazem uso intenso do livro, e por isso é importante pensar nas condições em que esta necessidade é produzida:

Quando se observa uma correlação entre o nível de instrução, por exemplo, e a quantidade de leituras ou a qualidade da leitura, podemos perguntar como isso se passa, pois não é uma relação autoexplicativa. É possível que se leia quando existe um mercado no qual possam ser colocados os discursos concernentes às leituras. Se esta hipótese pode surpreender, até chocar, é porque somos precisamente pessoas que têm sempre sob a mão um mercado, alunos, colegas, amigos, cônjuges etc., a quem podemos falar de leituras. Terminamos por esquecer que, em muitos meios, não é possível falar de leituras sem ter ar pretensioso ${ }^{8}$.

Na sequência do debate em que Bourdieu enunciou essas palavras, Roger Chartier argumentou que essa perspectiva é um tanto redutora, já que existem situações de leitura que independem de um mercado social, estando enraizadas em experiências individuais ou comunitárias. Ele dá o exemplo dos livros que serviam como guia para o trabalho em oficinas desde o século XVI. No entanto, esta dimensão para o qual Chartier aponta é complementar à de Bourdieu quanto ao uso pragmático e social que os leitores fazem dos textos em suas vidas (o produto do trabalho realizado com auxílio da leitura terá esse caráter). É a isso que remete a noção de uso social dos textos.

Uma biblioteca (escolar ou não) deve procurar atender, na medida do possível, às diferentes demandas quanto a esse aspecto, inclusive no que se refere a uma leitura tida como puramente informativa ou recreativa. É claro, uma biblioteca escolar deve ser bem abastecida pelos volumes dos clássicos, livros que os comentam e aqueles que os professores indicam; mas não deve negligenciar a assinatura de jornais, a aquisição de diferentes manuais úteis para a vida cotidiana e da literatura supostamente menor (romance policial, Harry Potter etc.), quando desejada. Isso não significa uma rendição à indústria cultural, mas sim um reconhecimento da multiplicidade das práticas da leitura e das possibilidades de complementaridade entre elas.

É verdade que se afirmou o elemento concorrencial entre as diferentes ofertas de textos. Porém, sendo a leitura afetada por uma série de variáveis, como o grau de instrução e as motivações do leitor, é impossível estimar o quanto o consumo de certo gênero ou tipo de texto, de fato e por si só, desestimula o consumo de outro. Mais importante é que a leitura de qualquer texto é a prova de uma chance para novas demandas. O estímulo a determinada prática cultural é, até certo ponto, mais difícil a partir da ausência de qualquer movimento do sujeito em relação a ela. Por isso, se por um lado as bibliotecas não devem agir como censoras do gosto, por outro, os professores devem entender os contextos da leitura de seus estudantes, de modo a tornar as leituras que privilegiam mais desejadas, sem por isso condenar outros consumos de textos.

Um exemplo interessante é dado por um leitor de Paulo Coelho, informante da pesquisa mencionada. Trata-se de um jovem estudante que surpreendia pela leitura diversificada e por apreciar os autores trabalhados na escola, em 
A experiência cultural da leitura - Richard Romancini

particular Graciliano Ramos. No entanto, considerava importante também a leitura de livros como Sabrina. Ao explicar a razão dessa leitura, sua resposta era exemplar, quanto à importância do uso social do texto: esse tipo de livro era um meio de obter melhor comunicação com as meninas, que, por sua vez, achavam Graciliano Ramos chato. A conclusão a que se pode chegar é simples: para a escola seria bem mais interessante tentar fazer com que as meninas também realizassem uma leitura significativa do autor de Vidas Secas, do que condenar o rapaz pela leitura de Sabrina.

\section{DA TEORIA À PRÁTICA}

Na teoria, o que se disse é muito positivo, mas como fazê-lo? Longe de oferecer um manual com um passo a passo, é válido oferecer alguns exemplos e sugerir estratégias. Nesse sentido, o depoimento de um professor de uma escola da periferia aponta para questões relevantes:

A maioria dos alunos brasileiros não compreende o que lê. [...] nossas escolas parecem estar formando analfabetos funcionais. Como reverter este quadro? [...] a escola brasileira precisa ensinar o aluno a ler.

Quando aluno, sempre fui um leitor voraz. Mas quando me tornei professor de português de escola pública, minha maior angústia era cumprir o cronograma, passar todo o conteúdo do livro didático, de forma que os alunos pudessem assimilá-lo até o final do ano letivo. Percebi que vencia do ponto de vista curricular, mas fracassava do ponto de vista educacional. Os conteúdos constituídos de exercícios e textos fragmentados não possibilitavam aos alunos desenvolverem seu senso crítico. Eu cumpria com o calendário, mas não estava formando leitores competentes.

Um dia, lecionando para uma turma de $3^{\circ}$ ano de Ensino Médio, eu estava sem qualquer disposição de continuar a lição do livro didático. Tive a ideia de ler um texto que estava no meio dos meus papéis, o conto A terceira margem do rio, de Guimarães Rosa. Antes de ler em voz alta propus aos alunos que elucidassem o mistério do paradeiro do pai na estória. Inicialmente houve apatia de muitos e uma má vontade generalizada da sala em ouvir uma estória chata, segundo eles. Mesmo assim insisti. Li devagar, fazendo todas as entonações. Minha voz se embargava à medida que eu me emocionava com o texto, e meus olhos enchiam-se de lágrimas. A emoção tomou conta da sala. Enquanto a narrativa prosseguia vi um aluno de 18 anos apoiar a cabeça sobre a carteira e desmanchar-se em lágrimas. Outros jovens choravam. Ao terminar a leitura perguntei o que havia de marcante no conto e foram unânimes ao dizer que era a ausência do pai. Começaram a falar sobre a beleza da estória e descobri que a maioria não havia conhecido a figura do pai. Alguns haviam ficado órfãos cedo, mas muitos eram filhos de pais desconhecidos ou que haviam abandonado o lar. Fiquei surpreendido com seu desejo de querer ouvir e ler mais textos de Rosa e outros escritores.

Passamos a ler e discutir textos de autores como Clarice Lispector e Lygia Fagundes. Pouco a pouco, meus alunos começaram a agir criticamente elogiando ou não as leituras, preferindo ou preterindo este ou aquele texto ou escritor. Minha fuga do rígido currículo havia valido à pena: todos se envolveram ${ }^{9}$.

9. MARQUES, Luiz. Por que eles não conseguem ler? Braudel Papers, n. 31, p. 2, 2002. 
10. PASSERON, Jean-Claude. O poliformismo cultural da leitura. In: O raciocínio sociológico. Petrópolis, RJ: Vozes, 1995. p. 380

11. OLIVEIRA, Raymundo de. Estudantes de Diadema superam dia a dia e encenam "Odisseia". Diário do Grande $A B C$ 15 dez. 2001. Disponível em: <http://www.circulosdeleitura.org.br/newsp5. html>. Acesso em: 15 mar. 2009.

12. Disponível em: <http://www.circulosdeleitura.org.br/>.
Neste relato pungente três pontos chamam a atenção: o vínculo que o professor percebeu entre o mundo dos leitores e o mundo de texto; a paradoxal dificuldade em compatibilizar as exigências do currículo e a formação de leitores, e a leitura oralizada. O primeiro aspecto mostra como o contexto sociocultural dos estudantes colaborou com a recepção. Pode-se dizer que a percepção de que a literatura abordava problemas que os afetavam foi um elemento importante para aproximá-los do que poderia ser uma estória chata. A importância da criação de vínculos entre a experiência de leitura e a vida é, aliás, bastante generalizável, sendo um indicador de sucesso em atividades de formação de leitores. Como nota Passeron, falando da leitura, "uma vez dados todos os meios de praticar, um grupo ou indivíduo só adota uma atividade se ela tiver um sentido ou puder tomar um sentido em sua cultura cotidiana" ${ }^{10}$. Essa ideia reencontra-se na fala de um jovem que participou de um projeto de leitura (descrito adiante), com o uso de clássicos: "Na minha odisseia só tem aparecido ciclopes. Palas Atenas que é bom, nada"

O segundo aspecto, a crítica a um currículo que parece dificultar a formação de leitores, remete a problemas da organização do ensino, seus objetivos e, também, quanto à educação de jovens dos grupos sociais economicamente desfavorecidos. Neste caso, geralmente, o capital cultural familiar, materializado na posse de livros e recursos para adquiri-los, é menor, o tempo para as atividades culturais é mais exíguo, em função do trabalho, e o estímulo à leitura é também menos intenso. Em tal cenário, é necessário que a escola crie estratégias que vão além das aulas de literatura, mas sem necessariamente excluí-las, para que a leitura tenha maior enraizamento.

Os grupos e encontros de leitura, nesse sentido, são possibilidades que merecem apoio. Algumas experiências vêm sendo feitas, como a do projeto Círculos de Leituras ${ }^{12}$, mencionado anteriormente, e que ajuda pequenos grupos de jovens de escolas públicas num programa de leituras e discussão de clássicos literários e atividades culturais associadas, como a adaptação teatral do que se lê. A leitura em voz alta (o terceiro aspecto a que se discute a seguir) também é utilizada. Iniciativa elogiável que deve, porém, estimular muitas outras, principalmente as que nasçam nas escolas e que possam, inicialmente ou em certos momentos, trabalhar leituras já realizadas pelos estudantes e articular-se ao incentivo à produção de múltiplas práticas culturais.

A sugestão de que os grupos discutam, por vezes, o que já é lido pelos estudantes (talvez livros como Harry Potter) objetiva facilitar um processo de expressão pessoal, de crítica e comparação do que se lê com outros parâmetros e opiniões diversas; oportunidade, portanto, de enriquecimento dessa experiência. Ao mesmo tempo, evita a noção de que o consumo da cultura está alhures, longe das práticas cotidianas. Nesse sentido, discussões sobre a literatura menos valorizada devem ser realizadas por mediadores sem preconceitos quanto a esse consumo, atentos às interpretações dos estudantes, e que saibam conduzir 
A experiência cultural da leitura - Richard Romancini

discussões plurais, conscientes de que o processo coletivo de argumentação é mais importante que as conclusões.

Assim também, a possível realização de discussões sobre o que já é lido pelos estudantes, nas aulas de literatura, pode ser um momento de esclarecimento e maior compreensão sobre o que está no programa. Um exemplo: pode ser interessante comparar a noção de amor que existe nos textos do movimento literário romântico e na novela sentimental de banca de jornal. O elemento comparado do estudo - que poderia desdobrar-se em aspectos como a linguagem, a influência social dos livros, seus leitores etc. - possibilita tornar mais marcante a apropriação da forma literária menos conhecida pelos alunos.

No âmbito da criação cultural que se pode estimular, além de encontros dos grupos entre si, dos grupos com escritores, elaboração de textos sobre o que se lê, existem possibilidades ligadas à educomunicação, com o uso dos meios de comunicação que a escola possua para socializar e enriquecer as leituras. A criação de blogs e boletins na internet pode favorecer os contatos e as trocas; nas escolas que possuem equipamentos radiofônicos e de vídeo, adaptações podem ser sugeridas. A leitura pode abrir-se para o mundo, além disso, através do incremento de práticas culturais ligadas a ela, como a visita a museus, lugares da cidade, frequência a cinemas, teatros etc.

\section{UM PASSO ESSENCIAL}

A leitura oralizada, que se destaca no depoimento do professor e no projeto Círculos de Leitura, foi algo que se observou também no caso de alguns dos leitores de Paulo Coelho. Sua importância está em indicar uma provável dificuldade da leitura que a oralidade tenta contornar. Passeron nota o mérito da aquisição de uma competência de leitura, que vá além da medida usual do alfabetismo, para a formação de leitores:

A leitura de livros só é rentável e/ou desejável sobre um limiar que define a "leitura rápida" (passagem direta do grafema ao significado sem intervenção do fonema). [...] [nem todos] possuem este domínio acelerado do código escrito, condição sine qua non de uma leitura que não seja um deciframento trabalhoso. Oferecer a leitura sem proporcionar todos os meios para ler não só é inútil, como também nefasto. [...] pregação ineficaz, por um lado, tensão e até rebelião ou desestímulo e autodesvalorização, por outro, criam as condições do perfeito mal-entendido ${ }^{13}$.

O autor refere-se à realidade francesa; a brasileira é certamente mais desafiadora quanto a esse passo essencial. Por isso, além de tudo que foi dito, talvez a mais importante tarefa da escola seja proporcionar uma efetiva competência de leitura a seus alunos. Sem isso, todas as iniciativas em prol da leitura serão dificultadas, assim com a noção de uma experiência cultural que envolva esta prática.

13. PASSERON, op. cit., p. 380 
comunicação \& educação • Ano XV • número 2 • maio/ago 2010

\section{REFERÊNCIAS BIBLIOGRÁFICAS}

BOURDIEU, Pierre; CHARTIER, Roger. A leitura: uma prática cultural. Debate entre Pierre Bourdieu e Roger Chartier. In: CHARTIER, Roger (Org.). Práticas da leitura. São Paulo: Estação Liberdade, 1996.

JOUVE, Vincent. A leitura. São Paulo: Ed. Unesp, 2002.

MARQUES, Luiz. Por que eles não conseguem ler? Braudel Papers, n. 31, 2002.

PASSERON, Jean-Claude. O poliformismo cultural da leitura. In: O raciocínio sociológico. Petrópolis, RJ: Vozes, 1995.

ROMANCINI, Richard. Apropriações de Paulo Coelho por usuários de uma biblioteca pública: leitura popular, leitura popularizada. Dissertação (Mestrado)Escola de Comunicações e Artes, Universidade de São Paulo, 2002.

\section{Endereços eletrônicos}

AMORIN, Galeno (Coord.). Retratos da leitura no Brasil: relatório de pesquisa promovida pelo Instituo Pró-Livro, 2008. Disponível em: <http://www.prolivro. org.br/ipl/publier4.0/dados/anexos/48.pdf>. Acesso em: 12 nov. 2009.

CÍRCULOS de leitura. Disponível em: <http://www.circulosdeleitura.org.br/>.

OLIVEIRA, Raymundo de. Estudantes de Diadema superam dia a dia e encenam "Odisseia". Diário do Grande ABC. 15 dez. 2001. Disponível em: <http://www. circulosdeleitura.org.br/newsp5.html>. Acesso em: 15 mar. 2009.

SÁEARP, Fábio; KORNIS, George. A economia do livro: a crise atual e uma proposta de política. IE/UFRJ. Texto para Discussão n. 004/2005, 2005. Disponível em: $<$ http://www.ie.ufrj.br/publicacoes/discussao/a_economia_do_livro_a_crise_ atual_e_uma_proposta_de_politica.pdf>. Acesso em: 12 nov. 2009. 